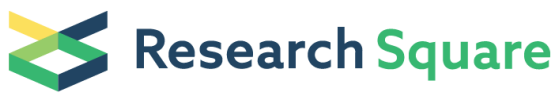 \\ Preprints are preliminary reports that have not undergone peer review. \\ They should not be considered conclusive, used to inform clinical practice, \\ or referenced by the media as validated information.
}

\section{Distribution of Serum Adiponectin Isoforms in Pediatric Patients with Steroid-Sensitive Nephrotic Syndrome}

\author{
Tetsuro Tamai \\ Showa University School of Medicine \\ Kaori Kamijo \\ Showa University Koto Toyosu Hospital \\ Yoshifusa Abe ( $\square$ yoshifusa@med.showa-u.ac.jp) \\ Showa University School of Medicine https://orcid.org/0000-0002-4861-8200 \\ Satoshi Hibino \\ Aichi Children's Health and Medical Center \\ Shunsuke Sakurai \\ Showa University School of Medicine \\ Shuichiro Watanabe \\ Watanabe Children's Clinic \\ Yoshitaka Watanabe \\ Showa University Yokohama Northern Hospital \\ Atsutoshi Shiratori \\ Tokyo Women's Medical University School of Medicine

\section{Satomi Nimura} \\ Showa University School of Pharmacy \\ Takaaki Takayanagi \\ Tokyo Metropolitan Health and Medical Treatment Corporation Ebara Hospital \\ Tsuneki Watanabe \\ Showa University Northern Yokohama Hospital

\section{Yuya Nakano} \\ Showa University School of Medicine \\ Hirokazu Ikeda \\ Showa University Fujigaoka Hospital \\ Kazushige Dobashi \\ Enzan Citizen Hospital \\ Yasuko Nakano \\ Yokohama University of Pharmacy \\ Katsumi Mizuno \\ Showa University School of Medicine \\ Kazuo Itabashi \\ Showa University School of Medicine
}

\section{Research article}

Keywords: Adiponectin, Adiponectin isoform, High-molecular-weight, Nephrotic syndrome, Children

Posted Date: May 13th, 2020

DOI: https://doi.org/10.21203/rs.3.rs-28091/v1

License: @ (1) This work is licensed under a Creative Commons Attribution 4.0 International License. Read Full License 
Version of Record: A version of this preprint was published at Clinical and Experimental Nephrology on June 1st, 2021. See the published version at https://doi.org/10.1007/s10157-021-02085-w. 


\section{Abstract}

Background Serum adiponectin circulates in three multimeric isoforms: high-molecular-weight (HMW), middle-molecular-weight (MMW), and low-molecular-weight (LMW) isoforms. Potential change in the circulating adiponectin levels in patients with nephrotic syndrome (NS) remain unknown. Therefore, this study aimed to assess the levels of total adiponectin and the distribution of its isoforms in pediatric patients with NS.

Methods We measured total adiponectin and each adiponectin isoform levels at the onset of NS, initial remission, and during the remission period of the disease in 31 patient with NS. We also calculated the ratios of HMW (\%HMW), MMW (\%MMW), and LMW (\%LMW) to total adiponectin and all values in 31 with those of 51 control subjects.

Results The mean total serum adiponectin levels in patients were $40.6 \pm 16.0 \mu \mathrm{g} / \mathrm{mL}, 41.1 \pm 18.5 \mu \mathrm{g} / \mathrm{mL}$, and $25.5 \pm 16.6 \mu \mathrm{g} / \mathrm{mL}$ at the onset of NS, at initial remission, and during the remission period of NS, respectively. These values were significantly higher than those in control subjects $(12.6 \pm 8.5 \mu \mathrm{g} / \mathrm{mL})$. The mean values of \%HMW, \%MMW, and \%LMW values were 57.0/28.0/14.2 at the onset of NS, 61.6/23.8/14.0 at the initial remission, and 58.1/21.7/17.7 at during the remission period, respectively. Compared with control subjects, \%HMW at initial remission and \%MMW at the onset of NS were high, and the \%LMW values at the onset of NS and at initial remission were low.

Conclusions In patients with NS, total serum adiponectin levels increase at the onset of the disease, and the ratio of adiponectin isoforms changes during the course of the disease. Further studies are needed to delineate the mechanisms between proteinuria and adiponectin isoforms.

\section{Introduction}

Adiponectin is an adipocyte-secreted protein that positively affects insulin sensitivity and coronary artery disease [1, 2].

Hypoadiponectinemia is associated with conditions such as insulin resistance, obesity, metabolic syndrome, type 2 diabetes mellitus, hypertension, dyslipidemia, and atherosclerosis [2,3]. Besides the reported associations in adults, plasma adiponectin levels in children are associated with several diseases, including obesity, insulin resistance, and Kawasaki disease [4-6].

In kidney diseases, the roles of adiponectin remain poorly understood; furthermore, results from different studies are controversial. Low adiponectin is correlated with albuminuria in both mice and humans [7]. Adiponectin knockout in mouse models leads to increased podocyte injury and albuminuria, whereas adiponectin therapies restore the podocyte foot processes [8]. However, in humans, significantly elevated serum adiponectin levels are reported in patients with chronic kidney diseases (CKD) or end-stage renal disease (ESRD) as well as in those who received dialysis or kidney transplants $[9,10]$. In addition, serum and urine adiponectin levels were positively correlated in both children and adults with focal segmental glomerulosclerosis [11]. Interestingly, patients with nephrotic syndrome (NS) with normal renal function have markedly increased serum adiponectin levels [12,13]. However, little is known about the mechanism of adiponectin upregulation in NS.

Adiponectin circulates in the form of three oligomeric complexes: high-molecular-weight (HMW, 400-600 kD, oligomer), middlemolecular-weight (MMW, $180 \mathrm{kD}$, hexamer), and low-molecular-weight (LMW, 75-90 kD, trimer) isoforms [1, 14]. In human serum, the percentages of HMW, MMW, and LMW in total adiponectin are approximately $40-50 \%, 25-35 \%$, and $25 \%$, respectively $[1,15]$. It has been suggested that the proportion of each sub-fraction determines the biological activities of adiponectin [16].The proportions of HMW and MMW are higher in females than in males [17]. Serum HMW adiponectin levels may be a better marker for predicting insulin resistance, metabolic syndromes, endothelial dysfunction, obese children, and type 2 diabetes mellitus than total adiponectin levels $[16,18]$. The HMW-to total adiponectin ratio may be positively associated with aortic stiffness in patients undergoing hemodialysis [19]. However, the effects of NS on the proportions of the adiponectin sub-fractions remain unknown. Therefore, we aimed to evaluate the effects of the nephrotic state on serum adiponectin levels and levels of each adiponectin isoform in patients with steroid-sensitive NS.

\section{Materials And Methods}

Thirty-one pediatric patients ( 23 males and 8 females; mean age $=4.1 \pm 3.3$ years) with newly diagnosed steroid-sensitive NS were admitted to our hospital from March 2006 to July 2019. Written informed consent was obtained from either one or both parents of each child before the enrollment in the study. This study was approved by the ethics committee of the Showa University School of Medicine (No. 759), and the study was performed according to the ethical standards of the 1964 Helsinki Declaration and its later amendments. 
Overall, 51 patients without clinically detectable kidney dysfunction ( 28 males and 23 females; mean age $=6.8 \pm 5.5$ years) were also enrolled in this study as control subjects. Blood was drawn from control subjects from January 2011 to September 2019. The following conditions presented in the control patients: seven were examined for health check-up; hydronephrosis and immunoglobulin A (IgA) vasculitis (including one patient with nephritis) in five patients each; asymptomatic hematuria and mycoplasmal infection in four patients each; acute pneumonia in three patients; acute otitis media, IgA nephropathy, simple goiter, and urticaria in two patients each; abnormal urinalysis, cervical lymphadenopathy, Hirschsprung disease, immune thrombocytopenic purpura, iron deficiency anemia, Kawasaki disease, neutropenia, nocturnal enuresis, protein losing enteropathy, renal scar, subcutaneous abscess, sepsis, thin basement membrane disease, thrombocytopenia, and vesicoureteral reflux in one patient each. Two control subjects had mild proteinuria with a urinary protein-to-creatinine ratio $(\mathrm{P} / \mathrm{Cr})<0.5 \mathrm{~g} / \mathrm{gCr}$, and six control subjects with Hirschsprung disease, IgA vasculitis, iron deficiency anemia, Kawasaki disease, protein losing enteropathy, and sepsis had hypoalbuminemia ( $<2.5 \mathrm{~g} / \mathrm{dL}$ ) without proteinuria.

The definition and criteria of NS used here are based on the clinical practice guidelines for pediatric idiopathic nephrotic syndrome 2013 [20]. A patient was considered to have NS if the proteinuria was $\geq 40 \mathrm{mg} / \mathrm{hr} / \mathrm{m}^{2}$ at night urine collection and the serum albumin level was $\leq 2.5 \mathrm{~g} / \mathrm{dL}$. Complete remission was defined as the qualitative resolution of proteinuria (negative by dipstick method) in the early morning urine for 3 consecutive days. Relapse was defined as positive results of protein $(\geq 2+)$ in the early morning urine for 3 days after remission. Steroid-sensitive NS was defined as NS conditions that completely remitted within 4 weeks after initiating of daily prednisolone therapy. According to the clinical practice guidelines for pediatric idiopathic nephrotic syndrome 2013, prednisolone treatment consisted of $60 \mathrm{mg} / \mathrm{m}^{2} /$ day or $2 \mathrm{mg} / \mathrm{kg} /$ day in three divided doses daily for 4 weeks, followed by $40 \mathrm{mg} / \mathrm{m}^{2} /$ day or $1.3 \mathrm{mg} / \mathrm{kg}$ once in the morning on alternative days for 4 weeks, or $40 \mathrm{mg} / \mathrm{m}^{2}$ or $1.3 \mathrm{mg} / \mathrm{kg}$ once in the morning on alternate days, continued for 2-6 months with tapering of the dose. [20].

Serum samples were stored at $-80^{\circ} \mathrm{C}$ until the time of adiponectin measurement. The levels of total serum adiponectin and the three adiponectin isoforms were analyzed using the enzyme-linked immunosorbent assay method and the Human Adiponectin ELISA Kit for total and multimers (Sekisui Medical Co. Ltd., Tokyo, Japan). To investigate the changes in the distribution of adiponectin isoforms at the onset of NS (before initiation of prednisolone treatment), at initial remission (just after detecting negative proteinuria by dipstick method), and the remission period after the initial remission of the disease, the ratios of HMW (\%HMW), MMW (\%MMW), and LMW (\%LMW) to total adiponectin were calculated for each time point.

Statistical analyses were performed using Prism 7 (GraphPad, San Diego, CA). Data are expressed as mean \pm standard deviation. Analyses included unpaired t-test and ANOVA with Dunnett's multiple comparison test. $P$ values $<0.05$ were considered significant.

\section{Results}

The clinical and biochemical characteristics for control subjects and for patients with NS are summarized in Table 1. At the onset of NS, the mean age of the 31 patients was $4.1 \pm 3.3$ years. The average duration of proteinuria after admission until the first day of initial remission was $9.2 \pm 3.6$ days. In two patients, serum creatinine levels were slightly elevated at the onset of NS. The average interval between the onset of NS and the third stage (the remission period after the initial remission) was $38.5 \pm 22.9$ days. No significant differences were found in ages or male-to-female ratios of the two groups (Mann-Whitney $\mathrm{U}$ test or chi-square test). Total protein and serum albumin levels in patients with NS were significantly lower at the onset and the initial remission stages than those in the control subjects. In contrast, total cholesterol levels were significantly higher at all three stages of the disease, and the triglyceride levels were significantly higher in patients at onset and in initial remission stages than in control subjects. No significant difference was found in the leptin levels between the two groups. After the treatment of initial NS, renal biopsies were performed in five patients because of frequent relapses of NS during their clinical courses. Minor glomerular abnormalities were found in all five patients during microscopic examinations. 
Table 1

Clinical characteristics and biochemical data of control subjects and patients with nephrotic syndrome

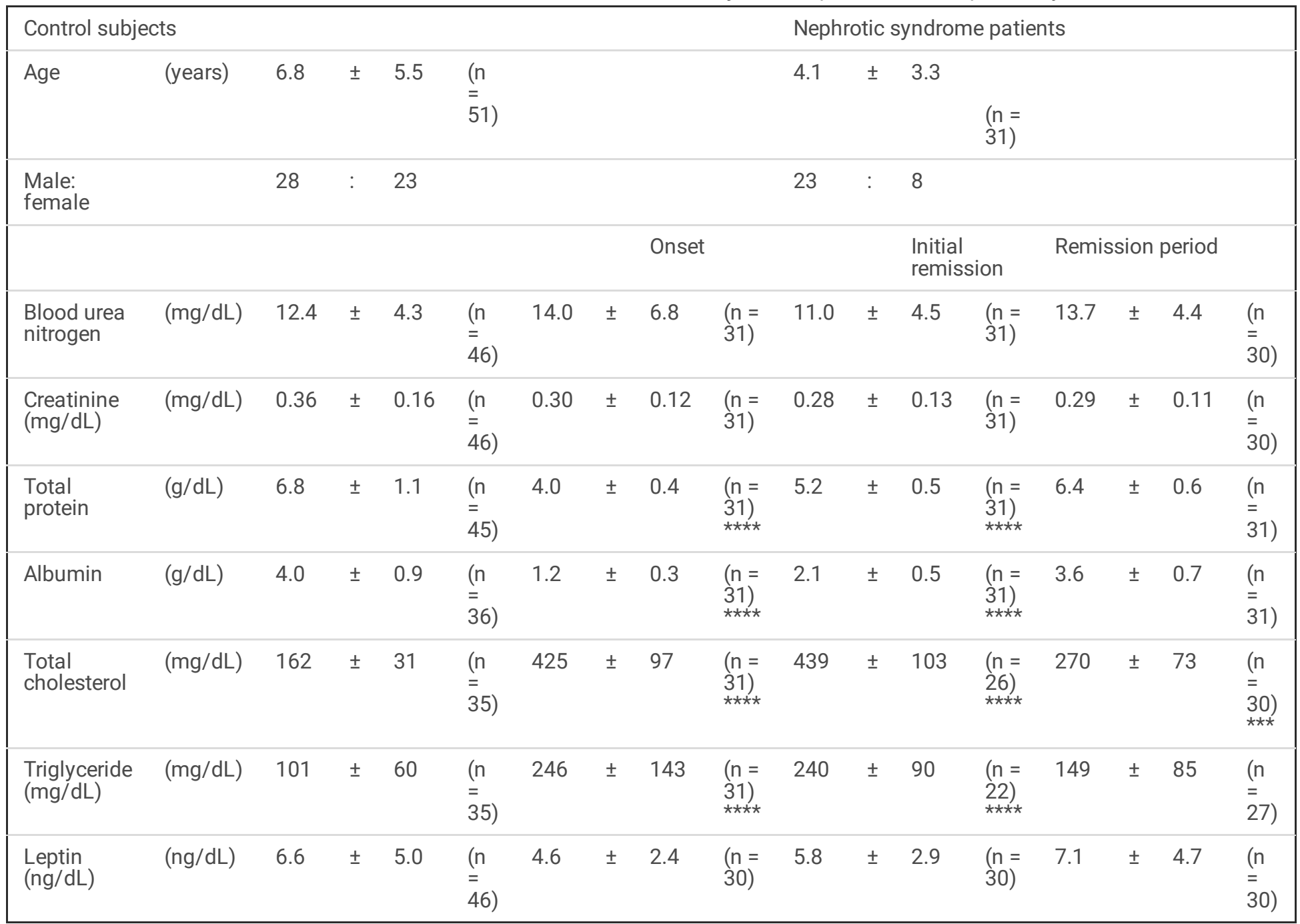

Total serum adiponectin levels were $40.6 \pm 16.0 \mu \mathrm{g} / \mathrm{mL}, 41.1 \pm 18.5 \mu \mathrm{g} / \mathrm{mL}$, and $25.5 \pm 16.6 \mu \mathrm{g} / \mathrm{mL}$ at the onset of NS, at initial remission, and during the remission period after initial remission of NS, respectively. In 51 control patients, the total serum adiponectin level was $12.6 \pm 8.5 \mu \mathrm{g} / \mathrm{mL}$ (Fig. 1). HMW adiponectin levels in the above three stages were $23.1 \pm 9.2 \mu \mathrm{g} / \mathrm{mL}, 25.2 \pm 10.5 \mu \mathrm{g} / \mathrm{mL}$, and $15.7 \pm$ $11.2 \mu \mathrm{g} / \mathrm{mL}$, respectively. In addition, MMW levels were $11.6 \pm 5.7 \mu \mathrm{g} / \mathrm{mL}, 10.0 \pm 4.6 \mu \mathrm{g} / \mathrm{mL}$, and $4.9 \pm 3.3 \mu \mathrm{g} / \mathrm{mL}$, respectively. Finally, LMW levels were $5.9 \pm 3.5 \mu \mathrm{g} / \mathrm{mL}, 6.4 \pm 5.8 \mu \mathrm{g} / \mathrm{mL}$, and $3.9 \pm 2.8 \mu \mathrm{g} / \mathrm{mL}$, respectively. Regarding the proportions of adiponectin isoforms at the above three stages, \%HMW were $57.0 \pm 6.9 \%, 61.6 \pm 9.4 \%$, and $58.1 \pm 10.0 \%$; \%MW were $28.0 \pm 6.2 \%, 23.8 \pm 6.9 \%$, and $21.7 \pm 7.1 \%$; and \%LMW were $14.2 \pm 7.2 \%, 14.0 \pm 6.8 \%$, and $17.7 \pm 8.9 \%$. In those 51 control subjects, HMW, MMW, and LMW levels were $6.8 \pm$ $5.2 \mu \mathrm{g} / \mathrm{mL}, 2.8 \pm 2.5 \mu \mathrm{g} / \mathrm{mL}$, and $2.9 \pm 1.7 \mu \mathrm{g} / \mathrm{mL}$, respectively. The \%HMW, \%MMW, and \%LMW were $51.4 \% \pm 11.7 \%, 23.0 \% \pm 7.0 \%$, and $25.6 \% \pm 9.9 \%$, respectively (Fig. 2 ).

Total adiponectin levels were significantly higher in patients in all three stages of the disease than those in control subjects. Even excluding control subjects with kidney diseases such as abnormal urinalysis (one patient), asymptomatic hematuria (four patients), IgA vasculitis with nephritis (one patient), IgA nephropathy (two patients), and thin basement membrane disease (one patient), the total adiponectin levels were significantly higher at all three stages of the disease (data not shown).

To investigate whether hypoalbuminemia is related to increased adiponectin levels, total serum adiponectin levels in six patients with hypoalbuminemia $(<2.5 \mathrm{~g} / \mathrm{dL}$ ) without proteinuria were compared wtih those in patients with NS. In those six patients, total serum adiponectin level was $18.3 \pm 15.7 \mu \mathrm{g} / \mathrm{mL}$. The total serum adiponectin level was significantly elevated at the onset of NS (40.6 \pm $16.0 \mu \mathrm{g} / \mathrm{mL})$ in patients with NS $(P<0.001$, Mann-Whitney U test).

Regarding adiponectin isoform levels in patients compared with those in control subjects, HMW, MMW, and LMW were all significantly higher $(P<0.0001)$ at onset and initial remission of NS. During the remission period, significantly higher HMW $(P<0.001)$ and MMW $(P<$ 
0.05) levels were observed. Regarding the proportion of the adiponectin isoforms, as compared with the control, \%HMW was significantly higher at the initial remission stage $(P<0.0001)$ and during the remission period $(P<0.05)$, \%MMW was significantly higher at the onset of NS $(P<0.01)$, and \%LMW was significantly lower at all three stages $(P<0.0001, P<0.0001$, and $P<0.01$, respectively) of NS.

\section{Discussion}

The advantage of this study was measuring both total adiponectin levels and the proportions of adiponectin isoforms, which had not been previously investigated in pediatric patients with NS. In this study, total adiponectin level increased significantly in pediatric patients with NS at the onset and initial remission of the disease compared with that in control subjects. We also observed increases in the levels of HMW, MMW, and \%MMW as well as a decrease in \%LMW at the onset of NS. These findings suggest that the total adiponectin level and the proportions of the adiponectin isoforms change in NS.

The finding of significantly increased adiponectin levels in patients with NS is consistent with that of previous reports [12, 13]. Zoccali et al. reported that the levels of serum adiponectin levels significantly increased in adult patients with NS secondary to different etiologic causes and were strongly related to the degrees of proteinuria [12]. Similarly, Bakkaloglu et al. reported that serum adiponectin levels remarkably increased in steroid-sensitive NS relapse compared with those in steroid-sensitive NS remission in pediatric patients [13]. The increase in adiponectin level parallels the progression of CKD, and high adiponectin levels are found in patients with ESRDs [21, 22]. In patients with CKD, uremia may reduce adiponectin clearance due to renal dysfunction and lead to impaired biodegradation and abolition [9]. However, adiponectin levels increase in patients with NS despite normal renal function. Therefore, uremic conditions and reduced clearance are unlikely to be associated with the increased adiponectin in NS.

The mechanism for elevated serum adiponectin levels and the direct effects of adiponectin on podocytes in the nephrotic state in NS remain unknown. However, increased serum adiponectin levels were unlikely to be associated with renal dysfunction because most patients with NS maintain renal functions. In urine, adiponectin exists largely as a trimer (LMW), which has a similar or lesser molecular weight than that of albumin [23-25]. Increased glomerular permeability due to podocyte dysfunction can cause hyper-filtration of adiponectin into urine. Hence, the changes in the distribution of adiponectin isoforms observed in our study may be associated with LMW leakage from the kidney. Recent evidence in mice suggests that the adiponectin regulates albuminuria and exerts a protective effect on the podocytes [8]. The adiponectin receptor (AdipoR1) is expressed at a high level in the podocytes and adiponectin signaling via adenosine monophosphate-activated protein kinase (AMPK) regulates NADPH oxidase 4 (Nox4) expression, which is linked to oxidative stress, the fusion of podocyte foot processes, and albuminuria [8]. These findings indicate a possibility that the adiponectin is upregulated in NS to attenuate podocyte damages. Zoccali et al. speculated an alternative possibility that the depletion of albumin and protein in NS triggers metabolic changes that may lead to hyperlipidemia and hyperfibrinogenemia in the liver as well as a parallel increase in the synthesis of adiponectin in fat cells [12]. This adaptation would be appropriate to limit the acute inflammatory phase reactions associated with NS [12]. In our study, three control patients had hypoalbuminemia $(<2.5 \mathrm{~g} / \mathrm{dL})$ without proteinuria or adiponectin elevation, which indicates that the prominent proteinuria, rather than the hypoalbuminemia was the trigger for the elevating adiponectin levels. Otherwise, elevated adiponectin levels in NS may be caused by an abnormal response to adiponectin in the kidney due to reduced AdipoR1 density, or signal coupling, or the production of an aberrant form of the molecule, as Sethna et al. implied [11]. It is difficult to know whether the increase in adiponectin levels occurs before the emergence of proteinuria, and thus, further investigations including animal studies are required to clarify the mechanisms of adiponectin upregulation and the its effects on the podocyte in NS.

There are few reports available on adiponectin isoform levels. Nishimura et al. reported that total serum adiponectin, HMW, MMW, and LMW levels are $5.5-6.4 \mu \mathrm{g} / \mathrm{mL}, 2.2-3.1 \mu \mathrm{g} / \mathrm{mL}, 1.6-1.8 \mu \mathrm{g} / \mathrm{mL}$, and 1.3-1.7 $\mu \mathrm{g} / \mathrm{mL}$, respectively, in school-age children [26]. Compared with those values, some of our patients with NS had higher levels for all adiponectin isoforms. Regarding the association between the adiponectin isoforms and diseases, the HMW levels may serve as a predictor of future cardiovascular events in patients with coronary artery disease, and the HMW-to-total adiponectin ratio may be positively associated with aortic stiffness in patients undergoing hemodialysis [1]. In addition, physiological activities, such as vascular protective activities and the insulin sensitivity, are also affected by HMW or \%HMW [19]. Pajvani et al. reported that the HMW-to-total serum adiponectin ratio is useful for monitoring the improvement of insulin sensitivity in response to thiazolidiones in cases of type 2 diabetes [27]. Goto et al. reported that decreases in LMW, HMW, and total adiponectin levels are associated with diabetes [28]. To the best of our knowledge, the changes in the proportion of adiponectin isoforms in NS have not been investigated previously. In our study, both HMW and the \%HMW increased in patients with NS, and thus, both HMW and \%HMW may promote the protection of podocytes.

This study has some limitations. First, all patients with NS were treated with steroids, and steroid treatment could affect adiponectin levels. Fallo et al. reported that the glucocorticoids decreased plasma adiponectin levels in males, as shown in both healthy subjects

Page 6/11 
receiving acute exogenous administration and patients with chronic endogenous hypercortisolism [29]. By contrast, steroids have an inhibitory effect on TNF-a, which decreases adiponectin level [30]. Uchida et al. reported that adiponectin levels were significantly augmented after glucocorticoid pulse therapy in patients with IgA nephropathy [31]. Furthermore, some reports have shown that steroids have no effect on the adiponectin level [32,33]. As mentioned above, the effects of steroid treatment on adiponectin are somewhat controversial, but many of studies suggest that steroid treatment increases adiponectin expression [34]. We emphasize that high serum adiponectin levels at the onset were under untreated condition and that all patients with NS were treated with steroids. Second, urine adiponectin levels were not measured in our study. The distribution of adiponectin isoforms in blood may differ from that in urine. In an experimental model, it is reported that the glucocorticoid-mediated tightening can reduce the flux of adiponectin across endothelial monolayers, possibly owing to alterations in the expression profiles of the tight junction proteins [35]. Therefore, the amount of each adiponectin isoform leaked from the kidney may be altered by the steroid treatment. Finally, only a small number of participants were enrolled in this study. Larger-scale studies are needed to further delineate the mechanisms between proteinuria and adiponectin complexes.

In conclusion, elevated serum adiponectin levels in patients with NS are believed to be secondary to proteinuria, but the mechanism remains unknown. This study suggests that total adiponectin levels and proportions of adiponectin isoforms change in the course of NS. A regulatory mechanism may exist between adiponectin and proteinuria.

\section{Declarations}

\section{Ethics approval and consent to participate}

This study was approved by the ethics committee of the Showa University School of Medicine (No. 759). An informed written consent was obtained from either one or both parents of each child before the enrollment in the study.

\section{Consent for publication}

Not applicable.

\section{Availability of data and materials}

Our database is available from the corresponding author on reasonable request.

\section{Competing interests}

The authors declare that they have no competing interests.

\section{Funding}

This work was supported by JSPS KAKENHI Grant Number JP17K10154 and Showa University Research Grant for Young Researchers in 2017 and 2019.

\section{Authors' contributions}

TT and YA collected and analyzed the data and drafted the manuscript. SH collected and analyzed the data. SS, SW, YW, TT, TW, AS, and $\mathrm{HI}$ collected the data and supported the clinical practice. KK and SN analyzed and interpreted the data. KM and KI provided valuable comments on the manuscript. YN, KD and YN provided critical comments on the manuscript.

\section{Authors' information}

A preliminary report was presented at the 51st Annual Meeting of the Japanese Society for Pediatric Nephrology, 2016 and the 54th Annual Meeting of the Japanese Society for Pediatric Nephrology, 2019.

\section{References}

1. Sun Y, Xun K, Wang C, Zhao H, Bi H, Chen X, Wang Y. Adiponectin, an unlocking adipocytokine. Cardiovasc Ther. 2009;27(1):59-75.

2. Fisman EZ, Tenenbaum A. Adiponectin: a manifold therapeutic target for metabolic syndrome, diabetes, and coronary disease? Cardiovasc Diabetol. 2014;13:103. 
3. Weyer C, Funahashi T, Tanaka S, Hotta K, Matsuzawa Y, Pratley RE, Tataranni PA. Hypoadiponectinemia in obesity and type 2 diabetes: close association with insulin resistance and hyperinsulinemia. J Clinical Endocrinol Metab. 2001;86(5):1930-5.

4. Tenhola S, Todorova B, Jääskeläinen J, Jänne OA, Raivio T, Voutilainen R. Serum glucocorticoids and adiponectin associate with insulin resistance in children born small for gestational age. Eur J Endocrinol. 2010;162(3):551-7.

5. Takeshita S, Takabayashi H, Yoshida N. Circulating adiponectin levels in Kawasaki disease. Acta Paediatr. 2006;95(10):1312-4.

6. Stefan N, Bunt JC, Salbe AD, Funahashi T, Matsuzawa Y, Tataranni PA. Plasma adiponectin concentrations in children: relationships with obesity and insulinemia. J Clinical Endocrinol Metabol. 2002;87(10):4652-6.

7. Sharma K. The link between obesity and albuminuria: adiponectin and podocyte dysfunction. Kidney Int. 2009;76(2):145-8.

8. Sharma K, Ramachandrarao S, Qiu G, Usui HK, Zhu Y, Dunn SR, Ouedraogo R, Hough K, McCue P, Chan L, et al. Adiponectin regulates albuminuria and podocyte function in mice. J Clin Invest. 2008;118(5):1645-56.

9. Jia T, Carrero JJ, Lindholm B, Stenvinkel P. The complex role of adiponectin in chronic kidney disease. Biochimie. 2012;94(10):2150-6.

10. Zoccali C, Mallamaci F, Tripepi G, Benedetto FA, Cutrupi S, Parlongo S, Malatino LS, Bonanno G, Seminara G, Rapisarda F, et al. Adiponectin, metabolic risk factors, and cardiovascular events among patients with end-stage renal disease. J Am Soc Nephrol: JASN. 2002;13(1):134-41.

11. Sethna CB, Boone V, Kwok J, Jun D, Trachtman H. Adiponectin in children and young adults with focal segmental glomerulosclerosis. Pediatr Nephrol. 2015;30(11):1977-85.

12. Zoccali C, Mallamaci F, Panuccio V, Tripepi G, Cutrupi S, Parlongo S, Catalano F, Tanaka S, Ouchi N, Kihara S, et al: Adiponectin is markedly increased in patients with nephrotic syndrome and is related to metabolic risk factors. Kidney Int Supp/2003(84):S98-102.

13. Bakkaloglu SA, Soylemezoglu O, Buyan N, Funahashi T, Elhan AH, Peru H, Fidan K, Yilmaz S, Hasanoglu E. High serum adiponectin levels during steroid-responsive nephrotic syndrome relapse. Pediatr Nephrol. 2005;20(4):474-7.

14. Dadson K, Liu Y, Sweeney G. Adiponectin action: a combination of endocrine and autocrine/paracrine effects. Front Endocrinol (Lausanne). 2011;2:62.

15. Beltowski J, Jamroz-Wisniewska A, Widomska S. Adiponectin and its role in cardiovascular diseases. Cardiovasc Hematol Disord Drug Targets. 2008;8(1):7-46.

16. Wang Y, Lam KS, Yau MH, Xu A. Post-translational modifications of adiponectin: mechanisms and functional implications. Biochem J. 2008;409(3):623-33.

17. Ebinuma H, Miyazaki O, Yago H, Hara K, Yamauchi T, Kadowaki T. A novel ELISA system for selective measurement of human adiponectin multimers by using proteases. Clin Chim Acta. 2006;372(1-2):47-53.

18. Araki S, Dobashi K, Kubo K, Asayama K, Shirahata A. High molecular weight, rather than total, adiponectin levels better reflect metabolic abnormalities associated with childhood obesity. Journal Clin Endocrinol Metab. 2006;91(12):5113-6.

19. Hara K, Horikoshi M, Yamauchi T, Yago H, Miyazaki O, Ebinuma H, Imai Y, Nagai R, Kadowaki T. Measurement of the high-molecular weight form of adiponectin in plasma is useful for the prediction of insulin resistance and metabolic syndrome. Diabetes Care. 2006;29(6):1357-62.

20. Ishikura K, Matsumoto S, Sako M, Tsuruga K, Nakanishi K, Kamei K, Saito H, Fujinaga S, Hamasaki Y, Chikamoto H, et al. Clinical practice guideline for pediatric idiopathic nephrotic syndrome 2013: medical therapy. Clin Exp Nephrol. 2015;19(1):6-33.

21. Iwashima Y, Horio T, Kumada M, Suzuki Y, Kihara S, Rakugi H, Kawano Y, Funahashi T, Ogihara T. Adiponectin and renal function, and implication as a risk of cardiovascular disease. Am J Cardiol. 2006;98(12):1603-8.

22. Stenvinkel P, Marchlewska A, Pecoits-Filho R, Heimbürger O, Zhang Z, Hoff C, Holmes C, Axelsson J, Arvidsson S, Schalling M, et al. Adiponectin in renal disease: relationship to phenotype and genetic variation in the gene encoding adiponectin. Kidney Int. 2004;65(1):274-81.

23. von Eynatten M, Liu D, Hock C, Oikonomou D, Baumann M, Allolio B, Korosoglou G, Morcos M, Campean V, Amann K, et al. Urinary adiponectin excretion: a novel marker for vascular damage in type 2 diabetes. Diabetes. 2009;58(9):2093-9.

24. Shen YY, Hughes JT, Charlesworth JA, Kelly JJ, Peake PW. Adiponectin is present in the urine in its native conformation, and specifically reduces the secretion of MCP-1 by proximal tubular cells. Nephrology (Carlton). 2008;13(5):405-10.

25. Jeon WS, Park JW, Lee N, Park SE, Rhee EJ, Lee WY, Oh KW, Park SW, Park CY, Youn BS. Urinary adiponectin concentration is positively associated with micro- and macro-vascular complications. Cardiovasc Diabetol. 2013;12:137. 
26. Nishimura R, Sano H, Shirasawa T, Matsudaira T, Miyashita Y, Ochiai H, Kokaze A, Tajima N, Utsunomiya K. Changes in the composition of adiponectin fractions over a 3-year period in children: a population-based cohort study. Child Obes. 2016;12(6):4405.

27. Pajvani UB, Hawkins M, Combs TP, Rajala MW, Doebber T, Berger JP, Wagner JA, Wu M, Knopps A, Xiang AH, et al. Complex distribution, not absolute amount of adiponectin, correlates with thiazolidinedione-mediated improvement in insulin sensitivity. $\mathrm{J}$ Biol Chem. 2004;279(13):12152-62.

28. Goto M, Goto A, Morita A, Deura K, Sasaki S, Aiba N, Shimbo T, Terauchi Y, Miyachi M, Noda M, et al. Low-molecular-weight adiponectin and high-molecular-weight adiponectin levels in relation to diabetes. Obesity (Silver Spring). 2014;22(2):401-7.

29. Fallo F, Scarda A, Sonino N, Paoletta A, Boscaro M, Pagano C, Federspil G, Vettor R. Effect of glucocorticoids on adiponectin: a study in healthy subjects and in Cushing's syndrome. Eur J Endocrinol. 2004;150(3):339-44.

30. Lele RD. Pro-insulin, C peptide, glucagon, adiponectin, TNF alpha, AMPK: neglected players in type 2 diabetes mellitus. J Assoc Physicians India. 2010;58(30):30-6.

31. Uchida HA, Nakamura Y, Kaihara M, Norii H, Hanayama Y, Sugiyama H, Maeshima Y, Yamasaki Y, Makino H. Steroid pulse therapy impaired endothelial function while increasing plasma high molecule adiponectin concentration in patients with IgA nephropathy. Nephrol Dial Transplant. 2006;21(12):3475-80.

32. Fukushima T, Hozumi A, Tomita M, Yonekura A, Miyata N, Miyamoto T, Taguchi K, Goto H, Tsuda K, Osaki M. Steroid changes adipokine concentration in the blood and bone marrow fluid. Biomed Res. 2016;37(3):215-20.

33. Braz NFT, Rocha NP, Vieira ÉLM, Gomez RS, Kakehasi AM, Teixeira AL. Body composition and adipokines plasma levels in patients with myasthenia gravis treated with high cumulative glucocorticoid dose. J Neurol Sci. 2017;381:169-75.

34. Sukumaran S, DuBois DC, Jusko WJ, Almon RR. Glucocorticoid effects on adiponectin expression. Vitamin Hormons. 2012;90:16386.

35. Dang TQ, Yoon N, Chasiotis H, Dunford EC, Feng Q, He P, Riddell MC, Kelly SP, Sweeney G. Transendothelial movement of adiponectin is restricted by glucocorticoids. J Endocrinol. 2017;234(2):101-14.

36. Legends.

\section{Figures}




\section{Total adiponection}

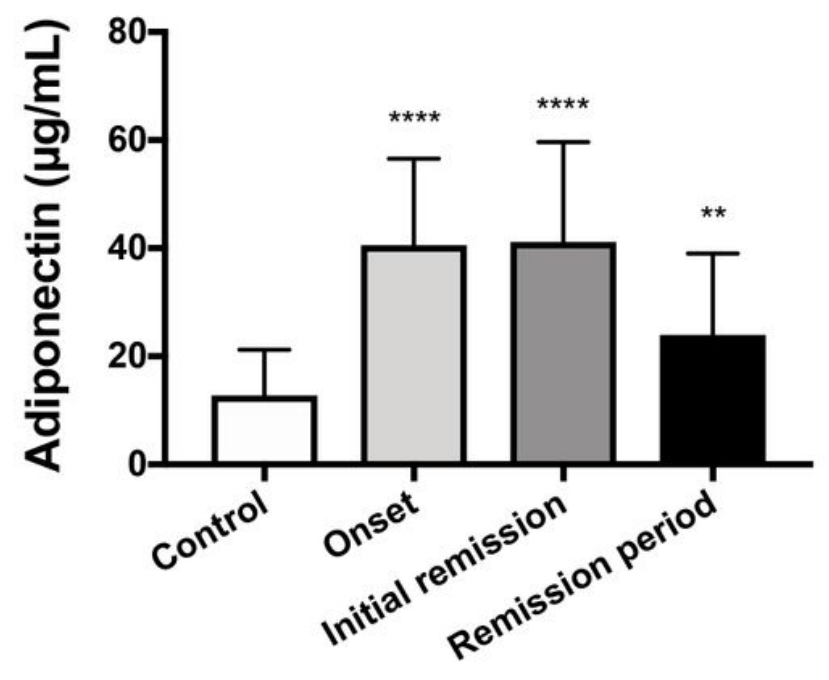

Figure 1

Figure 1

Mean serum total adiponectin levels. Statistical significance was calculated using ANOVA with Dunnett's multiple comparison test ${ }^{* \star} \mathrm{P}<$ 0.01 , and $* \star \star * ~ P<0.0001$. 

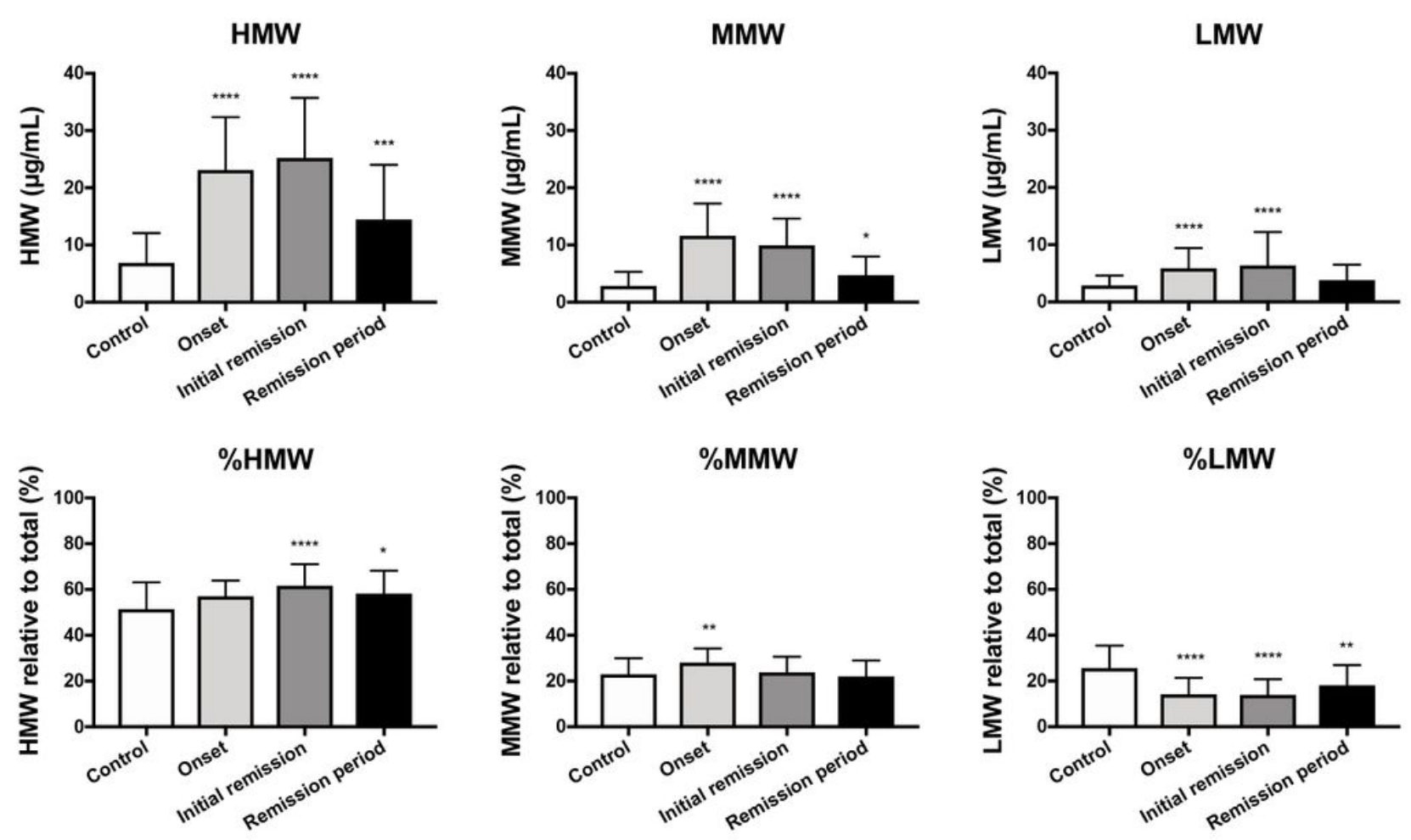

\section{Figure 2}

\section{Figure 2}

Mean serum adiponectin isoform levels. HMW, high-molecular-weight adiponectin; MMW, middle-molecular-weight adiponectin; LMW, low-molecular-weight adiponectin; \%HMW, ratio of HMW to total adiponectin; \%MMW, ratio of MMW to total adiponectin; \%LMW, ratio of LMW of total adiponectin.

\section{Supplementary Files}

This is a list of supplementary files associated with this preprint. Click to download.

- ResponsetoReviewers.docx 